\title{
PRODUÇÃO HEGEMÔNICA DO ESPAÇO: AVANÇO DO SETOR IMOBILIÁRIO E NOVAS CONTRADIÇÕES DO ESPAÇO EM JOÃO PESSOA
}

\author{
Hegemonic production of space: progress of the real state sector and new space \\ contradictions in João Pessoa \\ Rafael Faleiros de Padua* \\ *Professor do Departamento de Geociências e do PPG em Geografia - UPB - rfpadua@gmail.com.
}

Recebido em 09/05/2018. Aceito para publicação em 25/06/2018.

Versão online publicada em 10/08/2018 (http://seer.ufrgs.br/paraonde)

\begin{abstract}
Resumo: 0 crescimento urbano de João Pessoa revela uma transformação qualitativa que aponta para a instrumentalização do espaço no sentido da realização das estratégias dos agentes hegemônicos da produção do espaço. Essa produção estratégica do espaço faz avançar as fronteiras econômicas no urbano, aprofundando a fragmentação do espaço e da vida cotidiana e a segregação socioespacial.
\end{abstract}

Palavras-chave: produção estratégica do espaço; segregação socioespacial; urbanização de João Pessoa.

\begin{abstract}
The urban growth of João Pessoa reveals a qualitative transformation that points to an instrumentalisation of the space to the realization of the hegemonic agents strategies of the production of the space. This strategic production of the space advances as economic frontiers in the urban, deepening a fragmentation of space and everyday life and a sociospatial segregation.
\end{abstract}

Key-words: strategic production of the space; socio-spatial segregation; urbanization of João Pessoa.

\section{Introdução}

A cidade de João Pessoa vem passando nas últimas décadas por uma expressiva dinamização da produção imobiliária. De uma cidade que até a década de 1980 estava extremamente limitada em sua urbanização às atividades estatais ligadas ao fato de ser a capital do estado da Paraíba e a uma insipiente industrialização incentivada pelas políticas da SUDENE (DROULERS e RODRIGUEZ, 1981), hoje se verifica uma cidade que teve seu tecido urbano estendido de forma acelerada nas últimas décadas e que apresenta novas dinâmicas urbanas que apontam para progressiva transformação da terra urbana e dos lugares em novas fronteiras para a acumulação econômica.

Procuraremos apresentar nesse trabalho uma pesquisa que busca pensar a urbanização contemporânea de João Pessoa a partir das contradições geradas pela imposição de uma produção hegemônica do espaço, com o avanço do setor imobiliário para diversas regiões da cidade, produzindo grandes condomínios verticais ou horizontais. Essa dinamização do setor imobiliário revela uma produção espacial que consome uma parcela significativa do espaço da cidade, que produz lugares fechados à cidade, exclusivos para o uso das classes mais abastadas. Essa dinâmica pode ser observada nas regiões próximas à extensa orla da cidade, mas também em municípios vizinhos, sejam litorâneos como em cidades de serra, no interior, onde se observa a produção de condomínios fechados para a construção de casas de fim de semana das classes abastadas de João Pessoa.

Esse processo revela, para além do fechamento de grandes espaços à cidade, a produção de determinados modos de apropriação do espaço urbano, cada vez mais ligados a essas "novas produções". Ou seja, a reprodução das estratégias hegemônicas, ao mesmo tempo que transformam a 
morfologia urbana, produzem novos modos de usar a cidade, que se substanciam em um processo avançado de segregação socioespacial. Esses "novos produtos imobiliários", que se difundem para determinadas regiões da cidade, propõem uma sociabilidade anti-social, de negação da cidade, em uma vida fragmentada vivida em lugares específicos em momentos específicos, baseada no deslocamento de carro pela cidade. A expansão desses novos modos de usar o espaço urbano nega a cidade enquanto espaço da vida social e coletiva, onde os diferentes grupos sociais possam usar concretamente o espaço da cidade. Em João Pessoa, essa produção hegemônica do espaço é capitaneada por um número reduzido de empresas (incorporadoras, construtoras e imobiliárias) que são em sua maioria locais. Ou seja, é uma produção que apresenta uma ampla dominação sobre o espaço da cidade e, através da mediação do Estado, realiza suas estratégias com grande eficácia, a despeito do interesse da sociedade como um todo.

\section{Desenvolvimento}

Apresentaremos neste texto uma hipótese para uma interpretação da urbanização de João Pessoa no momento atual, de que a produção capitalista do espaço, dinamizada nos últimos 30 anos, de maneira cada vez mais marcante na própria paisagem da cidade, vai direcionando o crescimento urbano, tanto quantitativamente como qualitativamente, propondo/impondo novas maneiras de usar o espaço pelos moradores. Esse movimento revela o avanço da segregação socioespacial como resultado lógico do processo e ao mesmo tempo como contradição que se localiza na própria forma da vida urbana, na perspectiva de que a produção do espaço induz a novas formas de uso do espaço. Uma tendência homogeneizante do espaço produto se expressa no avanço da produção hegemônica do espaço, através das estratégias dos grupos econômicos que dominam a produção do espaço articulados às ações do Estado que dinamizam a transformação de novas regiões do espaço urbano em novas fronteiras econômicas para a acumulação do capital através da produção espacial.

Observamos, mesmo no momento atual de crise da produção econômica, um esforço das instituições ligadas ao setor imobiliário em criar novas tendências e consolidar a ideia do dinamismo desse setor em João Pessoa ${ }^{1}$. Além dos canais de comunicação próprios dos agentes hegemônicos da produção do espaço, a mídia escrita e televisiva também veiculam notícias que corroboram para a consolidação do dinamismo do setor imobiliário como investimento e a moradia como um produto cada vez mais elaborado. Se por um lado essas "notícias" evidenciam um movimento presente no espaço urbano de João Pessoa, ao mesmo tempo elas ajudam a conformar cada vez mais um ambiente favorável aos "novos produtos imobiliários". Ou seja, contribuem para que a mercadoria-espaço, produzida de modo refinado, com sempre renovadas especificações, se realize no espaço urbano, expandindo as condições de realização da cidade como negócio, onde todas as características naturais ou sociais possíveis são instrumentalizadas como álibis para a valorização. No espaço urbano de João Pessoa em expansão, verifica-se a crescente mercantilização do espaço e da natureza, que descaracteriza a própria paisagem ("natural" ou social) pretérita, e revela o uso produtivo da natureza, das "amenidades", e a formação de novos lugares no espaço urbano.

Hoje, para quem vê João Pessoa de longe, ou da praia em lugares com vista panorâmica, ou ainda para quem está no mar, verifica um horizonte com uma grande quantidade de prédios altos, não imediatamente na orla da cidade, mas não muito distantes dessa orla. Edifícios muito altos, alguns que chegam a 40, 50, 55 andares, muitos ainda em construção, concentrados em algumas regiões tanto na orla sul como na orla norte da cidade. Essa paisagem consolidada de um horizonte com uma grande quantidade de edifícios e o movimento de construção de grandes condomínios verticais que pode ser observada em algumas regiões da cidade nos apontam para uma dinamização da produção imobiliária que vem transformando o modo como a urbanização se reproduz em João Pessoa.

O litoral da cidade e suas proximidades é a região mais estratégica para os agentes hegemônicos

\footnotetext{
${ }^{1}$ A consulta em sites de entidades como Sinduscon ou mesmo em sites de jornais ou mídias digitais nos permitem verificar essa produção da ideia de dinamização do setor imobiliário em João Pessoa.
} 
da produção do espaço. Segundo Vasconcelos Filho, "pode-se afirmar que a cidade vem assumindo um perfil vertical, a partir de sua porção litorânea" (VASCONCELOS FILHO, 2003, p.93). Nesse sentido, duas regiões se destacam no espaço urbano de João Pessoa como estratégicas da expansão da produção imobiliária: a zona sul, que é a região que ainda tem maior disponibilidade de espaço não loteado a ser incorporado à urbanização; e a zona norte da cidade, nas proximidades do litoral, região que dinamiza também a produção imobiliária de Cabedelo, cidade conurbada a João Pessoa imediatamente ao norte. Na zona sul, onde se concentram grandes condomínios horizontais, mas também condomínios verticais (sobretudo no "bairro" Altiplano, onde se concentra uma acelerada produção imobiliária de edifícios para classes de alta renda), e mesmo em bairros mais periféricos, há a presença de condomínios horizontais fechados para classes mais abastadas. Da mesma forma, no município de Cabedelo, nas proximidades da BR-230, também se expandem condomínios horizontais, como continuação da própria urbanização de João Pessoa. Nessa breve caracterização, queremos apontar que as estratégias hegemônicas da produção do espaço envolvem grandes parcelas do espaço dessa aglomeração urbana, produzindo formas específicas de moradia que induzem a determinados modos de uso do espaço e que, sobretudo, provocam implicações sócioespaciais para todo o conjunto da população.

Há uma homogeneização de práticas que se expandem com os produtos condomínios verticais e horizontais. A qualidade do espaço cada vez mais ligada à valorização do espaço (ao espaço como mercadoria em processo de valorização, seja através da própria produção em consolidação e de forma concentrada em alguns lugares, seja também com a produção de equipamentos urbanos pelo Estado ou mudanças de legislação). A moradia (o imóvel) aparece cada vez mais como mercadoria, como um investimento. Nesse processo conduzido pela produção de determinados produtos imobiliários, se revela uma negação da cidade como objetivo almejado para a realização do produtomoradia, assim como o esvaziamento do espaço público, com a rua se colocando cada vez mais como lugar de passagem de carros, provocando o congestionamento em gargalos viários criados pela densificação de lugares pela verticalização.

A metamorfose que podemos observar em João Pessoa aponta para a necessidade de pensar a partir das práticas espaciais concretas as implicações do avanço da produção hegemônica do espaço como definidora do crescimento urbano.

O avanço dos "novos produtos imobiliários" traz consigo o crescimento de inúmeras atividades econômicas "acessórias" que participam desse processo, que são desenvolvidas como novas necessidades desse tipo de moradia que se expande. São inúmeros equipamentos e serviços que se realizam como ferramentas básicas para o funcionamento dos condomínios verticais e horizontais e que corroboram para refinar ainda mais a fragmentação do espaço e da vida cotidiana e para fazer avançar a segregação sócioespacial. A seguir elencaremos alguns desses "serviços" que aparelham cada vez mais a vida cotidiana e contribuem para envolver ainda mais os espaços-tempos da vida pela lógica de um cotidiano programado: - equipamentos e serviços de segurança privada; equipamentos e serviços de academia; - equipamentos e serviços esportivos; - serviços de paisagismo; - equipamentos e serviços de limpeza; - equipamentos de playground; - serviços de transporte especial (sobretudo escolar); - serviços de saúde residencial; - serviços de consultorias de todas as espécies para condomínios; - serviços financeiros; - serviços de administração condominial (profissionalização da administração); - equipamentos e serviços de decoração; - equipamentos e serviços de manutenção; - serviços diversos terceirizados; - equipamentos e serviços ambientais².

Enfim, a lista desses serviços disponíveis e cada vez mais presentes no cotidiano que se constitui no processo de transformação do espaço urbano poderia ser muito mais longa. No entanto acreditamos que esses itens aqui apontados já nos permitem indicar que, mesmo que muitos desses elementos não sejam exatamente novos, eles ganham um novo papel agora, no momento em que a moradia se refina como mercadoria e a vida cotidiana se vê povoada de equipamentos que a

\footnotetext{
2 Para a elaboração dessa lista usamos nossas observações depois de uma visita à Expo Casa e Condomínio - João Pessoa, no dia 10/06/2017, onde estavam presente os mais diversos expositores de equipamentos e serviços acessórios para condomínios e casas. Também consultamos o site da Revista Secovi de maio de 2017, in: http://www.revistasecovicondominios.com.br/, acesso em $14 / 06 / 2017$.
} 
fragmentam ainda mais. Dentre esses equipamentos e serviços, ressaltaríamos aqueles que se referem às questões de segurança, que fazem com que os espaços privados (mas também os públicos), sejam aparelhados com sistemas de controle e vigilância cada vez mais refinados. Esses sistemas afirmam a ideia da "necessidade" de espaços fechados à cidade e protegidos desta, fazendo com que os limites entre o espaço privado e o espaço público sejam cada vez mais impermeáveis, o que empobrece a vida urbana.

Trata-se de uma fragmentação ainda mais refinada do espaço, pois é o aparelhamento cada vez mais privado dos fragmentos fechados à cidade. É a negação do público, que transforma a cidade em mero conjunto de ruas e avenidas de passagens para carros. 0 avanço da "exclusividade" e da ideia de que a blindagem privada contra o diferente é solução para os problemas urbanos e a crise da cidade, revela a urbanização violenta, que produz violência, que é a força produtiva para a própria produção dos encastelamentos. Embora a fragmentação estrita e cada vez mais aperfeiçoada avance, ela não se realiza perfeitamente a não ser como discurso dos empreendedores imobiliários. A própria existência da cidade como concentração de elementos desiguais e diferentes coloca problemas para a realização da esfera da total privatização da vida. Os conflitos e as contradições do espaço que emergem no avanço da transformação do espaço urbano em mercadoria revelam que a cidade como lugar do encontro das diferenças necessariamente se recoloca no processo.

Todo o rol de equipamentos e serviços também nos aponta para a questão de que há um refinamento da moradia como uma mercadoria preenchida por outras mercadorias que a distanciam da cidade como algo coletivo e social, que necessariamente é. Esse povoamento da vida urbana com novas mercadorias que se colocam como novas mediações na apropriação da cidade, embora se refiram a determinadas classes sociais abastadas que podem consumir esse conjunto de coisas, contribuem para a configuração de lugares fragmentados no interior do tecido urbano, como se fossem pedaços individualizados, apartados da cidade, mas necessariamente não são. Ou seja, a produção dos lugares fragmentados tem implicações, que são sócioespaciais, e remetem a toda a cidade como totalidade. São as formas de usar a cidade que se colocam em questão e que são transformadas no movimento das estratégias espaciais que maximizam o espaço como mercadoria e a cidade como negócio.

O manejamento hegemônico do espaço da cidade precisa ser investigado em seus nexos entre os níveis do político, do econômico e do social, de modo que se evidencie de que forma o espaço vai sendo produzido através de estratégias que transformam concretamente o espaço da cidade, induzindo a novas formas de usar esse espaço por todo o conjunto da população. Quando apontamos o avanço e refinamento da segregação sócioespacial, queremos dizer que há um acesso desigual à cidade, de acordo com as classes sociais. Não remete simplesmente ao distanciamento físico das centralidades a que as classes pobres são submetidas, mas às privações em relação à cidade como um todo que esse distanciamento (e não somente ele, mas também as privações de todo tipo) já revela. É o uso concreto da cidade e de sua centralidade que a segregação remete, num contexto em que se afirmam as mediações do dinheiro e da propriedade privada da terra como forma de acesso à cidade.

A naturalização da lógica da mercadoria avançada no espaço faz com que o horizonte de lugar público da cidade seja cada vez mais desvalorizado. É como se fosse legítimos a dominação de amplas parcelas do espaço e o ato murá-las de modo a constituir formas de vida "exclusivas", retirando do conjunto da cidade possibilidades de trocas entre diferentes grupos sociais. A dimensão pública da cidade remete à sua totalidade como realização do homem social, o que as normatizações estatais não alcançam. Ganha terreno a perspectiva da cidade como negócio, e aí o espaço se torna eminentemente espaço estratégico. Assim inverte-se a lógica da cidade como lugar público, da realização da sociedade, mas os atributos que a sociedade como um todo produziu na materialização da cidade são manejados para a realização da abstração da acumulação. A cidade como o lugar da vida vai perdendo para a cidade como controle (estatal) e estratégia de acumulação (econômico).

Observamos em João Pessoa o movimento que vai das "amenidades naturais" da paisagem cênica da cidade à produção de novas raridades do espaço através da ação hegemônica do Estado e dos empreendedores imobiliários em ascensão nas diretrizes do crescimento urbano. A faixa litorânea da 
cidade vai sendo urbanizada de acordo com a expansão do setor imobiliário, que gradativamente vai produzindo "novas localizações". A dissertação de Mestrado de Maria Andreína Moreira Fernandes avança na investigação da produção de uma dessas novas localizações, o "bairro" do Altiplano, uma das principais regiões de valorização imobiliária da cidade.

Segundo ela,

O Bairro do Altiplano em João Pessoa é parte significativa de um dos mais expressivos cenários paisagísticos e turísticos da cidade, uma vez que está localizado sobre relevo particular devido a falésia que contorna todo o bairro: partindo da Ponta do Seixas, onde se configura a falésia viva (em contato com o mar), a barreira recua, formando uma moldura de falésia morta (sem contato com o mar) recoberta de Mata Atlântica, que se enxerga a partir da orla por trás dos prédios de baixo gabarito do Cabo Branco (FERNANDES, 2013, p.16).

0 "bairro" Altiplano, que em leis de zoneamento anteriores era considerada região com limitações para a ocupação, a partir de alteração na legislação municipal em 2007 que permite o adensamento, passa a ser uma das regiões prioritárias para as estratégias do setor imobiliário e se torna uma das regiões em processo vertiginoso de verticalização. Nesses últimos 30 anos evidencia-se a aceleração das estratégias dos agentes imobiliários como direcionadores do crescimento do tecido urbano, o Estado atua como mediação fundamental para a realização dessas estratégias. Ainda segundo Fernandes, "Uma parte do bairro, até então, considerada de restrições adicionais, passou a Zona de Adensamento Prioritário, de acordo com o Decreto Municipal no 5.844 aprovado em 08 de janeiro de 2007" (FERNANDES, 2013, p.116). Com essa mudança na legislação referente a ocupação de uma parcela do espaço urbano, o lugar rapidamente se transforma em um canteiro de construções de grandes edifícios residenciais (FERNANDES, 2013). Assim, o Estado se coloca como uma mediação fundamental para a conformação de novas fronteiras econômicas no urbano, não somente através das mudanças na legislação, mas também com a construção de obras viárias e de infraestrutura que permitem o adensamento das regiões e a consequente valorização do espaço.

Outros trabalhos de pesquisa também apontam para a concentração das estratégias do setor imobiliário em João Pessoa na sua região litorânea, tanto na Zona Sul como na Zona Norte (BARBOSA, 2005; VASCONCELOS, 2003). No caso da orla considerada Zona Norte, o processo de verticalização, sobretudo nos bairros de Tambaú e Manaíra, é mais antigo que o dinamismo atual observado nos bairros do Bessa (Norte) e Altiplano (Sul). Na zona norte, se trata, na história da urbanização da cidade, da transformação de bairros outrora distantes do centro e que eram lugares de casas de veraneio, em regiões de expansão da urbanização (VASCONCELOS, 2003). No caso da zona sul, a perspectiva de valorização de terras próximas ao litoral de João Pessoa fez com que grandes extensões se revelassem como estoques de terras ao movimento de expansão do tecido urbano para o sul.

0 apelo turístico também crescente da cidade se articula às estratégias do setor imobiliário, o que implica em uma intensificação das estratégicas de produção do espaço nas regiões com "amenidades", sobretudo nas proximidades da orla. Esse apelo contribui na construção da ideia de uma "qualidade de vida", que se coloca também como um álibi para a realização da produção hegemônica do espaço. No entanto, verificamos que embora as "amenidades" particulares da cidade e os seus "atrativos" próprios sejam importantes na produção das novas localizações, eles são envolvidos por produções espaciais que apontam para a generalização de um modo de vida urbano que impõe lógicas cuja concepção pouco estão ligadas às particularidades locais. É um modo de vida expandido a partir de uma morfologia de espaços fechados que se impõe nas cidades brasileiras independente do tamanho delas, embora sobressaiam nas maiores aglomerações urbanas e metrópoles.

Dessa forma, observamos que as transformações verificadas no espaço urbano de João Pessoa, cada vez mais capitaneadas pelos agentes hegemônicos da produção do espaço, impõem novas 
formas de apropriação do espaço urbano crescentemente mediadas pela lógica da realização da propriedade privada. Esse processo implica no avanço da fragmentação (do espaço e da vida cotidiana) e da segregação sócioespacial, ou seja, impõem novas contradições do espaço, que remetem ao uso concreto do espaço.

\section{Referências}

BARBOSA, Adauto Gomes. Produção do Espaço e Transformações Urbanas no Litoral Sul de João Pessoa. Dissertação de Mestrado. Programa de PósGraduação em Geografia. Universidade Federal do Rio Grande do Norte, 2005.

CARLOS, Ana Fani Alessandri. A reprodução do espaço urbano como momento da acumulação capitalista. In: CARLOS, Ana Fani Alessandri (Org.). Crise urbana. São Paulo: Contexto, 2015.

DROULERS, Martine; RODRIGUEZ, Janete Lins. João Pessoa. Crescimento de uma capital. João Pessoa: Fundação Casa de José Américo, 1981.

FERNANDES, Maria Andreína Moreira. A (Re)Produção do Espaço Urbano no Bairro Altiplano, João Pessoa-PB. Dissertação de Mestrado. Programa de PósGraduação em Arquitetura e Urbanismo, Universidade Federal da Paraíba, 2013.

MAIA, Doralice Sátyro. Desvendando o campo na cidade: notas metodológicas. In: Geotextos, vol.6, n.2, dez. 2010.

PADUA, Rafael Faleiros de. Produção estratégica do espaço e os "novos produtos imobiliários". In: ALVAREZ, Isabel Aparecida Pinto; CARLOS, Ana Fani Alessandri; VOLOCHKO, Danilo (Orgs.). A Cidade como Negócio. São Paulo: Contexto, 2015.

Revista Secovi, maio de 2017, in: http://www.revistasecovicondominios.com.br .

VASCONCELOS FILHO, João Manuel. A Produção e Reprodução do Espaço Urbano no Litoral Norte de João Pessoa-PB. Dissertação de Mestrado, Programa de Pós-Graduação em Geografia, Universidade Federal de Pernambuco, 2003. 